\title{
VILLA-LOBOS VINDICATED (AT LAST) A Pan-American Prescription
}

Villa-Lobos Justificado (finalmente!) Uma prescrição pan-americana

Jeremy John Haladyna ${ }^{1}$ Emeritus faculty, Univ. of California Santa Barbara haladyna@ucsb.edu 
Did Heitor Villa-Lobos, once arrived in Europe, truly say that Europeans would be studying him in time? This seems now open to debate. He certainly did say, however, that he had come to Paris not to study Europeans. At this juncture in the 21st century, we must ask why more young art composers of the Western Hemisphere have not been moved to follow his dictum. Does Europe continue to attract them for reasons of revitalization? Or rather, reasons of legitimization? If the former, much time and expense may be spared them.

In three specific areas, the New World has a rich cache of unexploited material that will long serve it by way of artistic revitalization. The first area is rhythm, the second is tuning, and the third is in contextualization. Now, even more than in Villa-Lobos' time, the New World has little reason to be aping the old. Let us pursue each of these in turn.

\section{Rhythm}

On the question of rhythm, indigenous peoples of this hemisphere are world masters in the realm of cycles. There certainly exists rhythm that is not cyclical, but what the world of art music craves-even demands at this point-is renewal in this domain of cyclical rhythm. Common duple and ternary schemes codified long ago in Europe, even the more recent asymmetrical variants such as 5/8,7/8,10/8, now qualify as "old news."

Perhaps it is time to look to the stars for new cycles, as our Mesoamerican forebears did. A host of intriguing discoveries in archaeoastronomy are there-all ready for musical interpretation. They only require reduction in scale to a workable size. But we need not look for such things only in times past. Today, in highland Guatemala, the Quiché Maya observe an interlocking schedule of ritual that is rhythmic-one they do in order to assure a successful harvest and long life to each participating lineage. It involves ascents to mountaintop shrines on particular days.

One series of their mountain ascents is made according to positioning of the moon (82 days), the other according to "quarter almanacs" of 65 days. [1 entire almanac $=260$ days $]$.

Barbara Tedlock, in her monumental book, Time and the Highland Maya, ${ }^{2}$ describes this dutiful, dual schedule as "imbricated," since the two cycles don't coincide. If the chosen word describing this seems not familiar, the picture it evokes certainly is: viz., imbricated roof tiles overlapping one another, but never actually one atop the other.

Tedlock's chronicles of these overlapping monthly observances were realized on a smaller, more tangible scale in the author's Demon Zero, part II, "Escalation." The result was surprising. If Europeanized 2/4 meter resembles the up and down motion of a reciprocating piston inside a car engine... if European 3/4 meter always mirrors the motion of a flywheel altogether round...then two overlaid Mayan mountain rhythms really make for something else! The rhythmic effect of them interacting in their complex dance seems

\footnotetext{
1 Teaching Professor Emeritus of Music at the College of Creative Studies, UCSB.

2 Barbara Tedlock, Time and the Highland Maya (Albuquerque, Univ. of New Mexico Press, 1992) pp. 190-197
} 
ovoid, slingshot. In sound, their cooperative dance suggests the rotor of a Wankel rotary engine tracing its eccentric pathway, which is nothing so simple as vertical.

And that's just a single result from one set of concurrent measurements: indigenous culture holds out the prospects of hundreds, many equally rife with musical implications.

\section{Tuning}

It is the second Pan-American domain, that of tuning, that has most preoccupied the author since the 1990s. Here, too, the implications of following a Western hemisphere path prove fertile.

These become particularly clear at the point where one attempts to construct, in so far as one can, a pre-Hispanic context for pitch. On this subject, books on organology, even those with a pre-Columbian focus, are vexingly vague. Should they make any pronouncements on the subject, it is to reinforce a stereotype that pentatony held sway as a near-universal tuning system.

No one disputes the wide prevalence of pentatony on Earth. But the author found hugely enlightening a visit he made in summer, 2012 to the workshops of Susan Rawcliffe of Long Beach, California, ceramic instrument-maker and world authority on pre-Columbian instrument construction. In addition to having played and studied thousands of such instruments, she manufactures her own instruments on the same acoustical principles. Ms. Rawcliffe is the recipient of several major grants, including one from the National Endowment for the Arts (U.S.).

In the course of purchasing several of her ceramic flutes for use in an upcoming work, the author was able to pose this very question, as to whether pentatony was indeed that ubiquitous and the best and only explanation for pitch "pre-Columbus."

Ms. Rawcliffe said certainly that it was not, that in her view what the pre-Columbians were doing above all was emulating the sounds of their natural environment. In this there were cultural and religious imperatives. This need to harmonize with nature took primacy over any pitch archetype, real or imagined. Here we surely have something closer to the truth: the uncanny sounds produced by a Mayan triple-chambered flute, for example, sound like nothing so much as electronic music-and that 13 centuries or more before this was born! Discrimination between those sounds produced by its three chambers, roughly-but not exactly-of the same length, has no direct acoustical analog save in modern multiphonics for wind instruments. And that, indeed, is just how this ancient flute sounds. Those who have ventured to the Belizean or Guatemalan selva know exactly what this instrument was meant to evoke: the unbroken whine of the small tree frogs near the watercourses, a chorus that begins at sunset and extends into the inifinite blackness of night.

Knowing all this, how is the young composer of the Western Hemisphere to react? For the approach of the brilliant Mayan manufacture here really suggests first, and foremost, sound design as it is now being practiced ubiquitously for both movies and television. No one today doing such work for media would suggest one could "get by" with a 
modicum of purely theoretical pitches drawn merely from an abstraction and neatly laid out on a monotimbral piano. That's true, even if the abstraction, and piano, should avail itself of partials moving well beyond the 32nd! A major adjustment must be reckoned today: sound design is going to play an integral role.

From the viewpoint of the Western hemisphere, then, today's new pitch exploration (that seeks the fundamentally new) can equally well proceed from an environmental basis, where observation and measurement promise rich harvests. Such direct observation and emulation is just as valid now as it was in the era of the ancients. And where new theoretical abstraction, new extrapolation is still craved, Mesoamerican calendrics and archaeoastronomy offer entirely new angles for this. Here, the author considers his eleven years devoted to the development of such new calendar scales time well spent, and a powerful and rewarding stimulus to new work.

\section{Contextualization}

The final element in which the Western Hemisphere holds an edge is in opportunity for the contextualization of art music. And here an odd truth holds sway: this advantage is a direct inheritance from the violent catacylism of the Conquest. The United States, Brazil, Canada, and Central and South America have been, and to a degree continue to be, in profound turbulence where cultural accommodation is concerned. But with music, that disruption is a positive that offers up new contexts.

It is this cultural accommodation and redefinition that-again and again-supply a niche for music to occupy. This is bound to happen where more fluid class structures and ongoing cultural reevaluation are factors. How ironic that the dramatic confrontations of our recent history, between European and indigenous American, African and Colonial, and now Ladino culture and indigenous culture, should be the very key to new innovation.

Where Europeans found music intimately tied to extant rituals and religion, they saw no alternative to its eradication, supplanting it with ritual and religion of their own. And thus the music of the Americas was forever changed. Today it is not a question of eradication, but of creative assessment.

The task before Pan-Americans now is to respond again with new rituals that resonate culturally. This is more difficult in a more secular age, but not impossible. There are authentic things we all experience that are so far devoid of music. Why should there not be music annually to help us transit from Standard time to Daylight Saving time, and vice-versa? This would be very much in the spirit of our Mesoamerican ancestors. Many of our ancestors here were migratory, moving with the seasons and celebrating the seasons. In Southern California, that might mean putting amplified players in convertibles or open vehicles and having them trace a migratory route, or a grid pattern in the streets of high significance.

The Mexican tradition of Las Mañanitas a la Virgen, each December 11th at midnight, provides an especially vibrant illustration of a winning context, one uniquely "Western hemisphere." If not high art music, it nonetheless remains a ritual with a door 
open, welcoming additions to an established repertoire. Given the honorific nature of the ritual singing to this New World Virgin, an effort to close down and codify for all time what can be sung or played on that night would be presumptive and false. And so, new canciones regularly appear to invigorate the ceremony, which possesses already a high cultural resonance, as witnessed by the thousands and thousands who attend or watch on television.

There is no mandate, however, that new music for rituals require in-person congregants. Sometimes, it may best profit the art composer today to work alone with the intention of creating his or her own context through digital media diffusion. In so doing, the sole artist becomes the spark that may ignite the latent cultural mixture, in order to fire the engine. The only requirement here is that the artist keep open the circle of the ritualistic invitation. A tie to a cultural element that promises not to fade with the passage of years can be a powerful way to draw consumers toward new work. Isolated historical events and crises of the moment fade; annual calendar constants do not. They work as a powerful adherent, latching onto themselves other works from artists of like mind.

Note well: this is a counter-recipe to the comparative abstraction of recent music from Europe (opera notably excepted), and technical extrapolations there rising from an already complex floor. Our Western hemisphere and its potential for new rhythms, new pitches and new ritual, with their attendant musics, here possesses all the advantages. 